\title{
STUDY OF ORBITAL MORPHOMETRY IN DRY SKULLS OF SOUTH
} INDIAN ORIGIN

\author{
Divya.C ${ }^{* 1}$, Swaroop Raj. B.V ${ }^{2}$, Venkateshu. K.V ${ }^{3}$.
}

${ }^{* 1}$ Assistant Professor, Department of Anatomy, Sri Devaraj Urs Medical College, Tamaka, Kolar, Karnataka, India.

${ }^{2}$ Assistant Professor, Department of Pathology, Sri Devaraj Urs Medical College, Tamaka, Kolar, Karnataka, India.

${ }^{3}$ Professor, Department of Anatomy, Sri Devaraj Urs Medical College, Tamaka, Kolar, Karnataka, India.

\section{ABSTRACT}

Introduction: The orbit is the cavity of the skull in which the eye and its appendages are situated. Orbital dimensions of skull vary in different races of mankind. Its dimensions are better understood by the knowledge of the orbital index. Normal values of orbital height, orbital width and orbital index are vital measurements in evaluation and diagnosis of craniofacial syndromes, interpretation of fossil records, skull classification in forensic medicine, anthropological investigation of unknown individuals for determining gender, ethnicity, etc and in exploring the trends in evolutionary and ethnic differences

Materials and methods: It is a cross sectional study conducted on 100 adult dry human skulls available in the Department of Anatomy, Sri Devaraj Urs Medical College, Kolar. The orbital dimensions were measured with the help of Vernier caliper.

Results: The mean orbital height for the right and left sides were $31.6 \pm 1.8 \mathrm{~mm}$ and $31.8 \pm 1.8 \mathrm{~mm}$ while, their orbital width were $37.4 \pm 2.1$ and $37.2 \pm 2.09 \mathrm{~mm}$ respectively. The mean orbital index was $84.49 \mathrm{~mm}$ on right and $85.48 \mathrm{~mm}$ on left side, and can be classified as Mesoseme category.

Conclusion: This study provides useful baseline orbital morphometric data of South Indian population, which are very important during ophthalmological, plastic surgery, maxillofacial, reconstructive cosmetic surgeries of face and neurosurgeries and also in the forensic research.

KEY WORDS: Orbital index, Orbital cavity, Mesoseme category.

Address for Correspondence: Dr. Divya. C, Assistant Professor, Department of Anatomy, Sri Devaraj Urs Medical College, Tamaka, Kolar, Karnataka, India. E-Mail: dr.divyac@yahoo.com

Access this Article online

Quick Response code

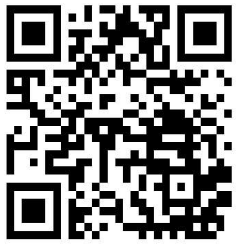

DOI: $10.16965 /$ ijar.2018.230

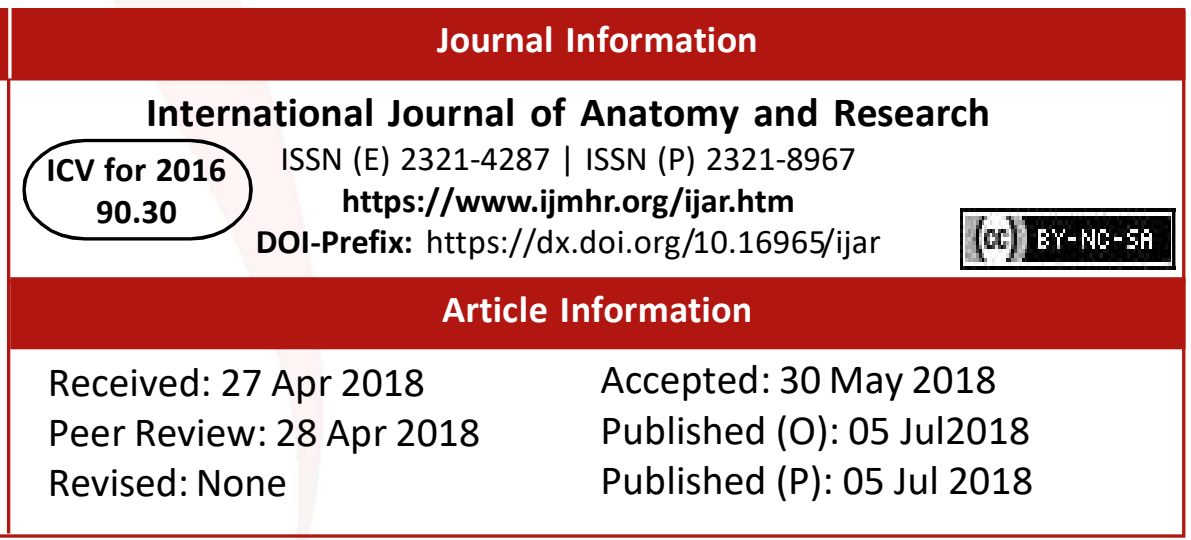

and neurosurgery [1]. Assessment of orbital dimensions is important for a good knowledge of the anatomical disposition of orbital structures and surgical management of orbital pathologies. Orbital anatomy is vital for surgical correction of the bony orbit to ensure an efficient structural disposition of the visual 
apparatus [2]. Orbital index varies in the different races of mankind and determines the shape of the face in different population groups, therefore knowledge of this index is important in various aspects such as in craniofacial database, interpretation of fossil records, skull classification in forensic medicine. Anthropology helps us to understand the anatomic structures of the orbit, and constitutes the technique of expressing makeover of human body and skeleton, for these reasons knowing the orbital index of different races by doing the regional studies is must for the better treatment[3]. Taking the orbital index as the standard, three classes of orbits have been described [4,5] as shown in table 1.

Table 1: Showing the classification of Orbital index.

\begin{tabular}{|c|c|c|}
\hline Type & Orbital Index & Commonly Seen In \\
\hline $\begin{array}{c}\text { Megaseme } \\
\text { (large) }\end{array}$ & 89 or more & Yellow races \\
\hline $\begin{array}{c}\text { Mesoseme } \\
\text { (intermediate) }\end{array}$ & 89 to 83 & $\begin{array}{c}\text { White races } \\
\text { (European 87, English } \\
88.4)\end{array}$ \\
\hline $\begin{array}{c}\text { Microseme } \\
\text { (small) }\end{array}$ & 83 or less & Black races \\
\hline
\end{tabular}

Many studies have been done to measure orbital cavity dimensions using radiographs and CT $[6,7]$. This anthropometric study employs the use of direct measurements on dry skulls as it will present a different and a more natural perspective in assessing the orbital cavities.The present study was aimed at documenting standard values of orbital indices in a south Indian group and comparing it with available data from other populations of the world. These would be very useful in anthropological studies, craniofacial surgery and diagnosis of craniofacial anomalies. The significance of this study is that it serves as a guide for surgeons who resort to reconstructive management of fractures secondary to traumas and different orbital pathologies.

Objectives: The objectives of the present study are

1. To provide the normal reference orbital parameters for the South Indian population.

2. To assess and classify the type of orbital index in dry skulls of South Indian origin.

\section{MATERIALS AND METHODS}

It is a cross sectional study conducted on 100 adult dry human skulls available in the Department of Anatomy, Sri Devaraj Urs Medical College, Kolar. Only normal skulls were selected for the study. Skulls with craniofacial malformations or fractures were excluded from the study. The measurements are taken from different points of all the orbits. The following parameters were measured with the help of Vernier caliper calibrated in millimeters,

1. Orbital length: maximum distance between the upper and lower margins of the orbital cavity.

2. Orbital Breadth: distance between the midpoint of the medial margin of the orbit to the midpoint on the lateral margin of the orbit.

3. Orbital Index: orbital length/orbital breadth $\times$ 100.

Fig. 1: Orbital Length of the Skull.

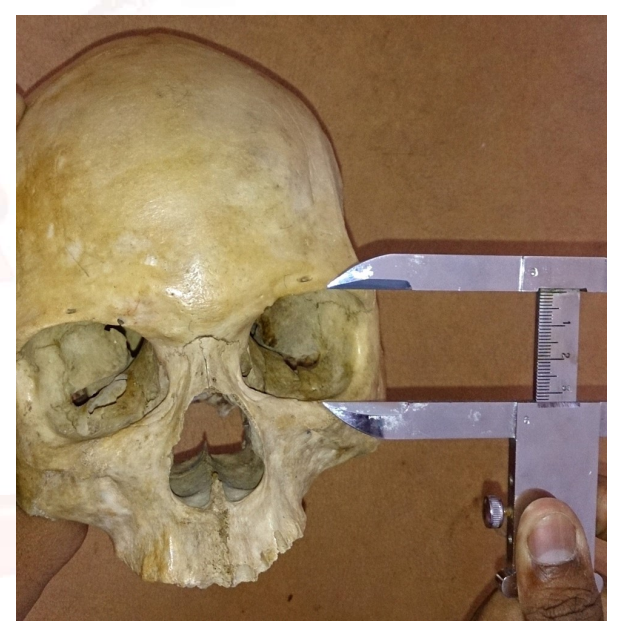

Fig. 2: Orbital Breadth of the Skull.

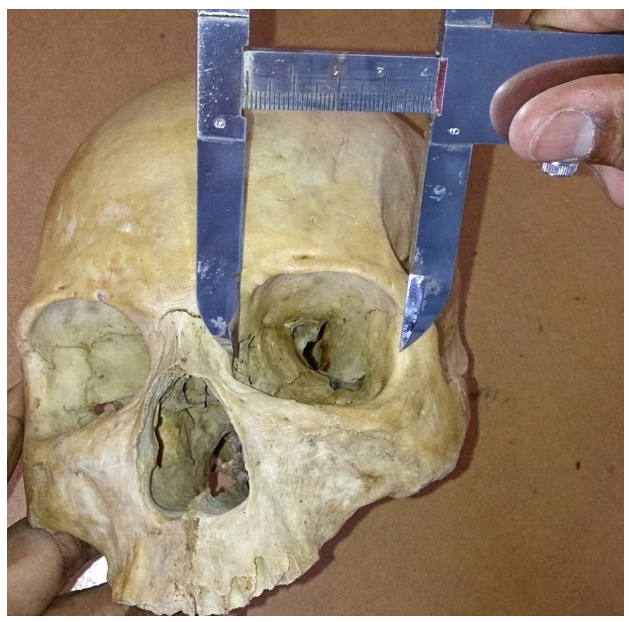

\section{OBSERVATIONS}

In the present study it was found that the mean orbital length is $31.6 \mathrm{~mm}$ on both right and left side, orbital breadth on right was found to be $37.4 \mathrm{~mm}$ and $37.2 \mathrm{~mm}$ on left side. Mean orbital 
index was found to be $84.64 \mathrm{~mm}$ on right and $85.29 \mathrm{~mm}$ on left side, as shown in table 2 .

Table 2: Comparison of Orbital length, Orbital breadth and Orbital Index between right and left side orbits.

\begin{tabular}{|c|c|c|c|}
\hline Orbital Dimension & Side & Mean & $\begin{array}{c}\text { Standard } \\
\text { Deviation }\end{array}$ \\
\hline \multirow{2}{*}{ Orbital Length } & Right & 31.6 & 1.8 \\
\cline { 2 - 4 } & Left & 31.8 & 1.8 \\
\hline \multirow{2}{*}{ Orbital Breadth } & Right & 37.4 & 2.1 \\
\cline { 2 - 4 } & Left & 37.2 & 2.09 \\
\hline \multirow{2}{*}{ Orbital Index } & Right & 84.49 & 4.73 \\
\cline { 2 - 4 } & Left & 85.48 & 4.79 \\
\hline
\end{tabular}

\section{DISCUSSION}

Morphometric parameters of orbit are important in ophthalmology, oral maxillofacial surgery and neurosurgery. Orbital index has been employed to determine the sex of a person in forensic medicine. The orbital index which determines the shape of the face differs in different population groups. This means that the orbits with larger widths than height will have smaller orbital indices while those with larger orbital indices will have narrow faces. This index varies with race, regions within the same race and periods in evolution. The present study aimed to compare the orbital index of the South Indian population with available data from other populations of the world, as shown in table-3.

Table 3: Comparison of orbital index of previous studies with present study.

\begin{tabular}{|c|c|c|c|c|}
\hline SI.No & Author & Region & Orbital index & Category \\
\hline 1 & Ukoha U et al.[3] & Nigeria & 89.21 & Megaseme \\
\hline 2 & Ebeye and Otikpo[8] & Urhobos & 78.36 & Microseme \\
\hline 3 & Munguti.J et al[9] & Kenya & $\begin{array}{c}82.57 \text { (male) } \\
83.48 \text { (female) }\end{array}$ & $\begin{array}{l}\text { Microseme } \\
\text { Mesoseme }\end{array}$ \\
\hline 4 & Kaur et al.[10] & North india & 81.65 & Microseme \\
\hline 5 & Gosavi S.N. et.al[11] & Maharashtra & 81.88 & Microseme \\
\hline 6 & Mekala.D. et.al[12] & South India & $\begin{array}{c}84.62 \text { (male) } \\
85.46 \text { (female) }\end{array}$ & $\begin{array}{l}\text { Mesoseme } \\
\text { Mesoseme }\end{array}$ \\
\hline 7 & Present study & South India & $\begin{array}{l}84.49 \text { (right) } \\
85.48 \text { (left) }\end{array}$ & $\begin{array}{l}\text { Mesoseme } \\
\text { Mesoseme }\end{array}$ \\
\hline
\end{tabular}

Results from this study show that the orbital index of this population is 84.49 on right and 85.48 on left side. This places this group of adult South Indian population in the Mesoseme category. Our findings are in accordance with study done by Mekala.D. et al. on South Indian population. Weaver et al., in their CT scan based study in Caucasian subjects observed mean orbital height as $32.09 \pm 2.2 \mathrm{~mm}$ and orbital width as $37.01 \pm 2.0 \mathrm{~mm}$, orbital index as 85.66 , which belongs to Mesoseme category[9]. Ebeye and Otikpo in Urhobos subjects of Nigeria observed mean $\mathrm{OH}$ as $32.46 \mathrm{~mm}$, mean $\mathrm{OW}$ as $41.53 \mathrm{~mm}$ and orbital index as 78.36, which puts this population into Microseme category [10]. The slight difference observed between the right and left side, though not significant, could be attributed to the differential growth of the two sides of the brain and in this case, the right side has shown dominance. A factor that must be considered in the surgical correction of the bony orbit to ensure an efficient structural disposition of the visual apparatus. Many factors have been implicated in the transformation of the facial skeleton into the adult form. Although the basic structure is determined in accordance with genetically regulated blueprints while in utero, that is modified pre and postnatally through functional matrices responding to environmental and epigenetic influence such as climate, activity patterns and masticatory functions [13]. Variation of orbital index between and within the population could be due to genetic and environmental factors.

Normal values of orbital indices are vital measurements in the evaluation, and diagnosis of craniofacial syndromes and post traumatic deformities, and knowledge of the normal values for a particular region can be used to treat abnormalities to produce the best aesthetics and functional result. For these purposes, standards based on local data are desirable, since these standards reflect the different patterns of craniofacial growth resulting from racial, ethnic, social and dietary differences.

\section{CONCLUSION}

This study done on the orbital index of south Indian adult dry skull provides useful baseline orbital morphometric data, for clinical and surgical treatment in ophthalmology, oral and maxillofacial surgery, plastic surgery and neurosurgery and also in the design of eye protective equipment. The knowledge of this index is therefore important in various aspects such as in skull classification in forensic medicine, interpretation of fossil records, anthropological investigation of unknown individuals for determining gender, ethnicity and in exploring the trends in evolutionary and ethnic differences. 


\section{Conflicts of Interests: None}

\section{REFERENCES}

[1]. Patnaik V.V.G., Bala Sangu, Singla Rajan K. Anatomy of the Bony Orbit-Some Applied Aspects. J Anat.Soc. India. 2001;50(1):59-67.

[2]. Sayee Rajangam, Kulkarni R.N, Lydia Quadrilos, et al. Orbital dimensions. Indian Journal of Anatomy. 2012;1:5-10.

[3]. Ukoha U, Egwu OA, Okafor IJ, Ogugua PC, et al. Orbital dimensions of adult male Nigerias: a direct measurement study using dry skulls. International Journal of Biological and Medical Research. 2011; 2(3): 688-690.

[4]. Mcgraw Hill, dictionary of scientific and technical terms "mesoconch" Mcgraw hill company Inc, answer.com (homepage on the internet) 2003; Retrieved from http:/www.answer.com/topic/mesoconch.

[5]. Cassidy, P., 1913. Megaseme" Webster dictionary. Answer.com (homepage on the internet) Retrieved from http://www.answer. com/topic/megaseme.

[6]. Leko Bankole J, Douglas Promise, Ukoima H.S, Madugba Christopher. Radiological Assessment of Orbital Dimensions of the Kalabaris and Ikwerres of Rivers State, Nigeria. Afr. J. Biomed. Res. 2012;15:197 - 200 .
[7]. Weaver AA, Loftis KI, Tan JC, DumaSM, Stitzel JD. CT scan based three-dimensional measurement of orbit and eye anthropometry. IOVS. 2010; 51(10): 4892-7.

[8]. Ebeye O.A, Otikpo O. Orbital Index in Urhobos of Nigeria. IOSR Journal of Dental and Medical Sciences. 2013; 8(2):51-53.

[9]. Munguti Jeremiah, Mandela Pamela, Butt Fawzia. Sex differences in the cranial and orbital indices for a black Kenyan population. Int. J. Med. Sci. 2013;5(2):81-84.

[10]. Kaur J, Yadav S, Sing Z. Orbital dimentions - A direct measurement study using dry skulls. J. Acad. Indus. Res. 2012; 1(6):293-5.

[11]. Gosavi S. N., Jadhav S. D., Zambre B. R. A study of orbital morphometry in Indian dry skulls. Asian Journal of Biomedical and Pharmaceutical Sciences. 2014; 04 (29): 23-25.

[12]. Mekala D, Shubha R, Rohini Devi M. Orbital dimensions and orbital index: a measurement study on South Indian dry skulls. Int J Anat Res. 2015;3(3):1387-1391.

[13]. Vidarsdotir US, OHiggins P, Stinger C. A geometric morphometric study of regional differences in the ontogeny of the modern human facial skeleton. Journal of Anatomy. 2002; 201(3):211.

\author{
How to cite this article: \\ Divya.C, Swaroop Raj. B.V, Venkateshu. K.V. STUDY OF ORBITAL \\ MORPHOMETRY IN DRY SKULLS OF SOUTH INDIAN ORIGIN. Int \\ J Anat Res 2018;6(3.1):5449-5452. DOI: 10.16965/ijar.2018.230
}

